\title{
Gastrointestinal stromal tumor of the small bowel mimicking a gas-fluid collection
}

\author{
Sergio Savastano, ${ }^{1}$ Luca Boi, ${ }^{1}$ Emanuele S.G. d'Amore ${ }^{2}$ \\ ${ }^{1}$ Department of Radiology; ${ }^{2}$ Department of Pathology, San Bortolo Hospital, Vicenza, Italy
}

\begin{abstract}
A 74-year-old alert woman presented to the Emergency Department for abdominal pain, vomit, diarrhea and low grade fever. She had a blood pressure of $120 / 60 \mathrm{mmHg}$, a pulse rate of $106 \mathrm{bpm}$ and $\mathrm{O}_{2}$ saturation of $100 \%$. Physical examination showed abdominal distension, diffuse tenderness but without rebound tenderness. Routine blood tests showed elevation of white cell blood count $\left(18.4 \times 10^{9} / \mathrm{L}\right)$, increase of serum C-reactive protein $(45.4$ $\mathrm{mg} / \mathrm{dL})$ and procalcitonin $(17.95 \mathrm{mg} / \mathrm{dL})$. In the suspicion of an intestinal occlusion a radiographic study of the abdomen was performed; the radiography in erect view showed a huge gas-fluid collection with an irregular superior aspect and a gas-fluid level; entrapped gas bubbles were also evident below the gas-fluid niveau (Figure 1). A chest plain film was normal. A contrastenhanced computed tomography (CT) of the abdomen, immediately performed, detected a mass with a thin rim enhancement, gas and fluid-like content on scans (Figure 2). A communication with the bowel was supposed but not definitively demonstrated. Provisional differential diagnosis included a giant inflammatory diverticulum and perforation of a duplication intestinal cyst. The patient was thereafter operated on a laparotomy; surgical exploration revealed a $24 \mathrm{~cm}$ exophytic cavitated mass fistulized to the small bowel, which were resected. Histology in a solid area showed a proliferation of bland spindle cells (Figure 3), positive for CD117 and DOG-1 at immunohistochemistry. The final diag-
\end{abstract}

Correspondence: Sergio Savastano, Department of Radiology, San Bortolo Hospital, v.le F. Rodolfi 37, 36100 Vicenza, Italy.

Tel.: +39.0444.753490 - Fax: +39.0444 .753839 .

E-mail sergio.savastano@aulss8.veneto.it

Key words: Gastrointestinal stromal tumour; Radiological features; Gastrointestinal imaging.

Contributions: the authors contributed equally.

Conflict of interest: the authors declare no potential conflict of interest.

Funding: none.

Received for publication: 27 March 2018.

Revision received: 21 May 2018.

Accepted for publication: 28 May 2018.

This work is licensed under a Creative Commons Attribution 4.0 License (by-nc 4.0).

(C) Copyright S. Savastano et al., 2018

Licensee PAGEPress, Italy

Emergency Care Journal 2018; 14:7448

doi:10.4081/ecj.2018.7448 nosis was exophytic gastrointestinal stromal tumor (GIST) of the small bowel with extensive cystic changes due to coagulative necrosis, with low mitotic activity, high risk. ${ }^{1}$ Large GISTs show often cystic change at presentation; approximately $50 \%$ of them are fistulized to the gastrointestinal tract at the diagnosis. ${ }^{2}$ Cystic appearance with a thin contrast-enhanced rim on CT scans is rare and usually found in rapidly growing GISTs. ${ }^{3}$ Differential diagnosis of an abdominal cavitated lesion includes more common causes like abscess, large diverticulum, duplication intestinal cyst or pancreatic pseudocyst perforated in the bowel. Nevertheless a GIST with cystic changes and gastrointestinal fistulization should be also considered in the preoperative diagnosis. Detection of the Torricelli-Bernoulli $\operatorname{sign}^{2}$ (i.e. presence of a nondependent intratumoral gas collection directed towards the necrotic orifice on axial imaging), can suggest the correct diagnosis.

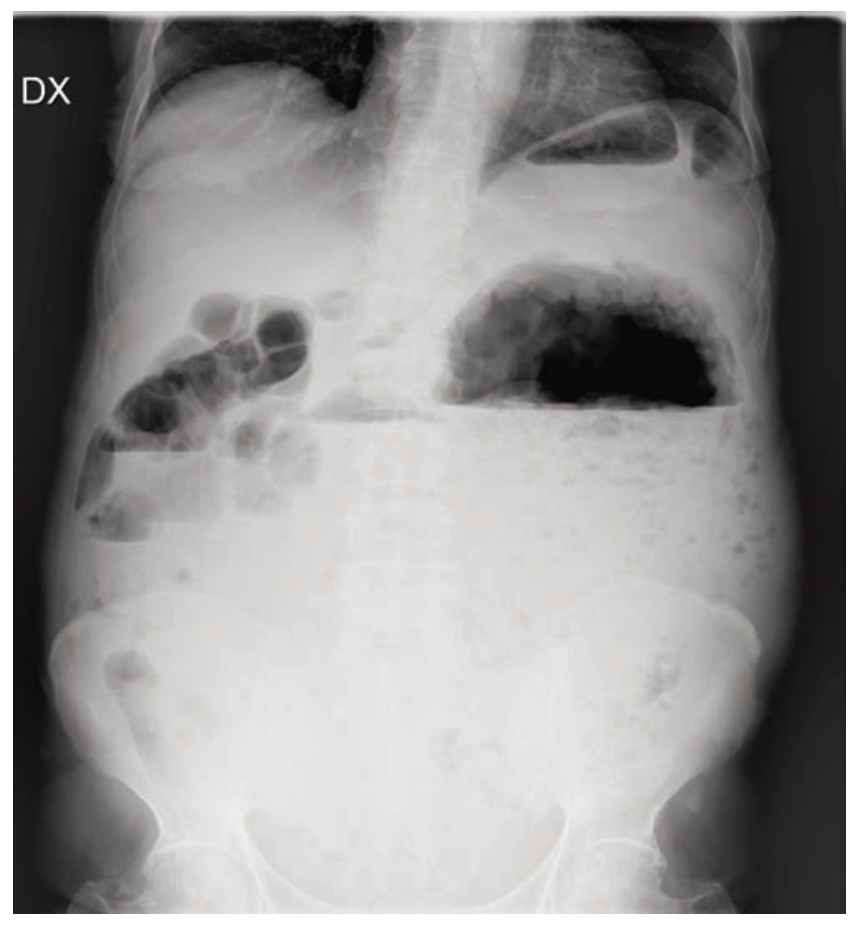

Figure 1. A huge gas-fluid collection at the left flank is evident on plain radiography of the abdomen (erect view); several gas bubbles are appreciable below the gas-fluid level. 

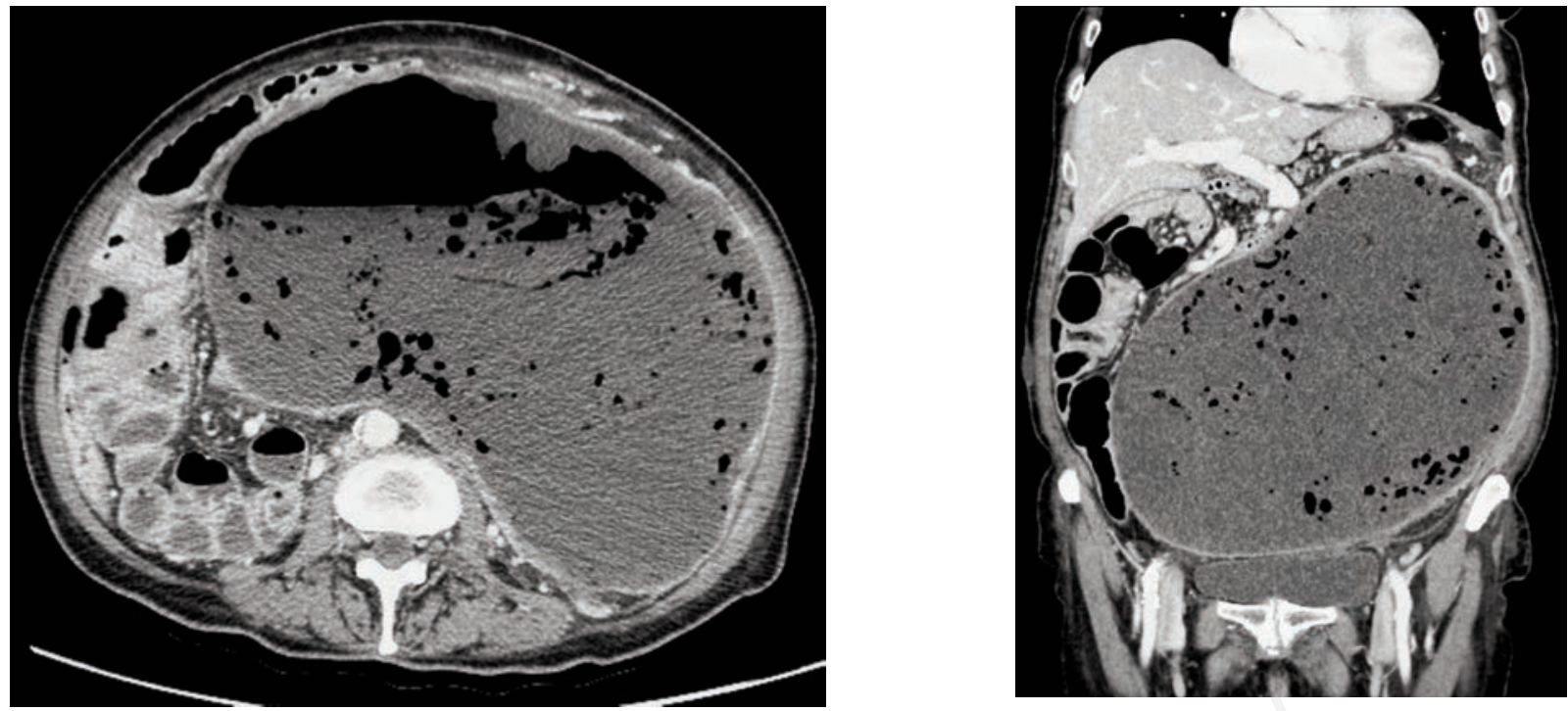

Figure 2. Contrast-enhanced CT. (A) The gas-fluid collection shows a thin peripheral rim; (B) Coronal reformation. CT scans did not demonstrated an intraperitoneal fluid collection (not shown).

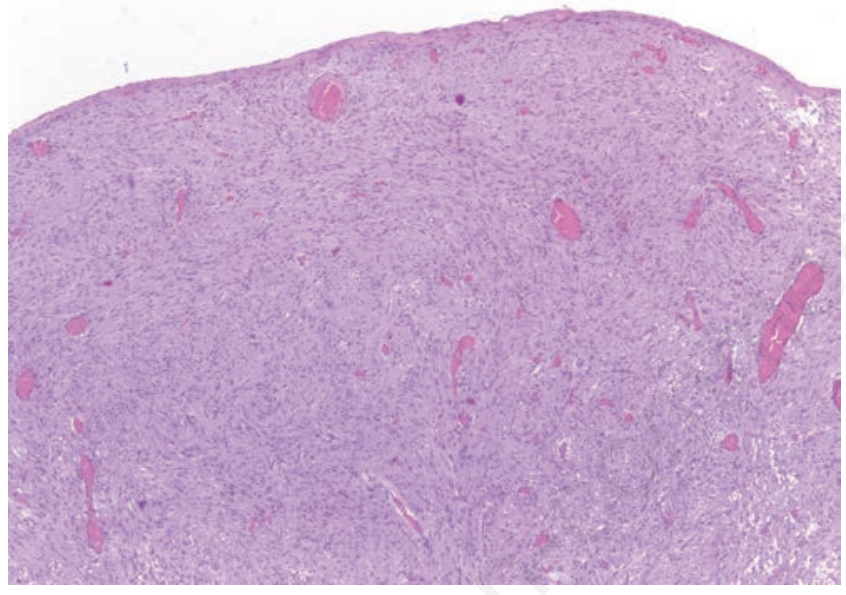

\section{References}

1. Miettinen M, Makhlouf H, Sobin LH, et al. Gastrointestinal stromal tumors of the jejunum and ileum: a clinicopathologic, immunohistochemical, and molecular genetic study of 906 cases before imatinib with long-term follow-up. Am J Surg Pathol 2006;30:477-89.

2. Sandrasegaran K, Rajesh A, Rydberg J, et al. Gastrointestinal stromal tumors: clinical, radiologic, and pathologic features. AJR Am J Roentgenol 2005;184:803-11.

3. Kumar A, Jakhmola CK, Chauhan SS, et al. Atypical presentation of gastrointestinal stromal tumor masquerading as a large duodenal cyst: A case report. Int J Surg Case Rep 2015;9:1236 .

Figure 3. Histology shows showing a proliferation of bland spindle cells with low mitotic activity. 